\title{
A BULK-DRIVEN CMOS OTA WITH 68 dB DC GAIN
}

\author{
Jonathan Rosenfeld, Mücahit Kozak, and Eby G. Friedman \\ Department of Electrical and Computer Engineering \\ University of Rochester \\ Rochester, New York 14627-0231
}

\begin{abstract}
An ultra-low voltage rail-to-rail operational transconductance amplifier (OTA) based on a standard digital $0.18 \mu \mathrm{m}$ CMOS process is described in this paper. Techniques for designing a 0.8 volt fully differential OTA are discussed including bias and reference current generator circuits. To achieve rail-to-rail operation, complementary input differential pairs are used, where the bulk-driven technique is applied to reduce the threshold limitation of the MOSFET transistors. The OTA gain is increased by using auxiliary gain boosting amplifiers. This additional circuitry enables the OTA to operate at 0.8 volts, achieving an open loop gain of $68 \mathrm{~dB}$ while consuming $94 \mu \mathrm{W}$. The DC gain of the amplifier is the highest gain achieved to date in bulk-driven amplifiers.
\end{abstract}

\section{INTRODUCTION}

The reduction in the minimum dimensions in VLSI technologies along with the trend of using small portable devices necessitates reduced power supply voltages. In order to facilitate submicrometer high density systems on a single integrated circuit (IC), voltage levels must be lowered to ensure reliability. Threshold voltages of future CMOS technologies may not decrease much below what is available today, making it difficult to design ana$\log$ circuits with lower supply voltages.

In analog circuit design, the threshold voltage of a transistor should be lowered in proportion to the reduction in the supply voltage to appropriately bias the device. This characteristic makes standard low voltage analog circuits incompatible with CMOS technology trends. To combat this conflict without requiring the development of expensive CMOS technologies with lower threshold voltages, novel circuit design techniques must be developed that are compatible with future CMOS technologies.

A promising approach in low voltage analog circuits is the socalled "bulk-driven" MOSFET method. In this method, the gateto-source voltage is set to a value sufficient to form an inversion layer, and an input signal is applied to the bulk terminal. In this

\footnotetext{
* This research was supported in part by the Semiconductor Research Corporation under Contract No. 2003-TJ-1068, the DARPA/ITO under AFRL Contract F29601-00-K-0182, the National Science Foundation under contract No. CCR-0304574, the Fullbright Program under Grant No. 87481764, grants from the New York State Office of Science, Technology \& Academic Research to the Center for Advanced Technology Electronic Imaging Systems and to the Microelectronics Design Center, and by grants from Xerox Corporation, IBM Corporation, Intel Corporation, Lucent Technologies Corporation, and Eastman Kodak Company.
}

manner, the threshold voltage of a MOSFET can be reduced or even removed from the signal path.

The concept of a bulk-driven MOS transistor was first proposed by Guzinski et al. in 1987 [1] as active components in an OTA differential input stage. Later, in 1991, the concept was used in the practical realization of a software-programmable CMOS telephone circuit [2]. However, not until 1998 [3] did the method draw significant attention as a viable low-voltage analog design technique. Specifically, in [3], a 1 volt Op Amp was designed in a standard CMOS digital process utilizing the depletion characteristics of bulk-driven transistors.

One important drawback of the bulk-driven method, however, is that the body transconductance $g_{m b}$ is approximately five times smaller than the gate transconductance $g_{m}$. Thus, when the input differential pair of an amplifier is composed of bulk-driven transistors, the resulting DC gain is relatively low. This behavior is the primary reason for the low gain (around $45 \mathrm{~dB}$ ) in previously reported bulk-driven amplifiers [3], [4].

In this paper, a 0.8 volt fully differential folded-cascode OTA is presented. Both PMOS and NMOS bulk-driven input differential pairs are used to achieve full rail-to-rail operation. A continuoustime common mode feedback circuit is adopted in order to suppress variations in the output common mode. Four commonsource gain boosting amplifiers are used to increase the gain to the target level of $68 \mathrm{~dB}$ (the DC gain was around $48 \mathrm{~dB}$ before gain boosting). This gain is the highest gain achieved to date in bulk-driven amplifiers. A bias circuitry which generates the required bias voltages for the amplifier core along with a low sensitive reference current generator circuit are also presented

This paper is organized as follows. The design of the amplifier core is presented in Section 2. In Section 3, the bias circuit and reference current generator are described. In Section 4, the circuit layout is presented. In section 5, the performance of the amplifier is summarized and some conclusions are offered in Section 6.

\section{THE AMPLIFIER CORE}

The amplifier core of an OTA is illustrated in Figure 1. This circuit is based on a fully differential topology with two complementary input pairs. The output branch consists of common gate amplifiers with cascode current loads to increase the gain. A common mode feedback circuit is used with four auxiliary common source amplifiers. The operation of the OTA is explained in greater detail below.

\subsection{Rail-to-Rail Operation}

Rail-to-rail operation is achieved using a pair of PMOS $\left(\mathrm{M}_{5}\right.$ and $\left.\mathrm{M}_{6}\right)$ and NMOS $\left(\mathrm{M}_{33}\right.$ and $\left.\mathrm{M}_{34}\right)$ transistors at the input stage. This 


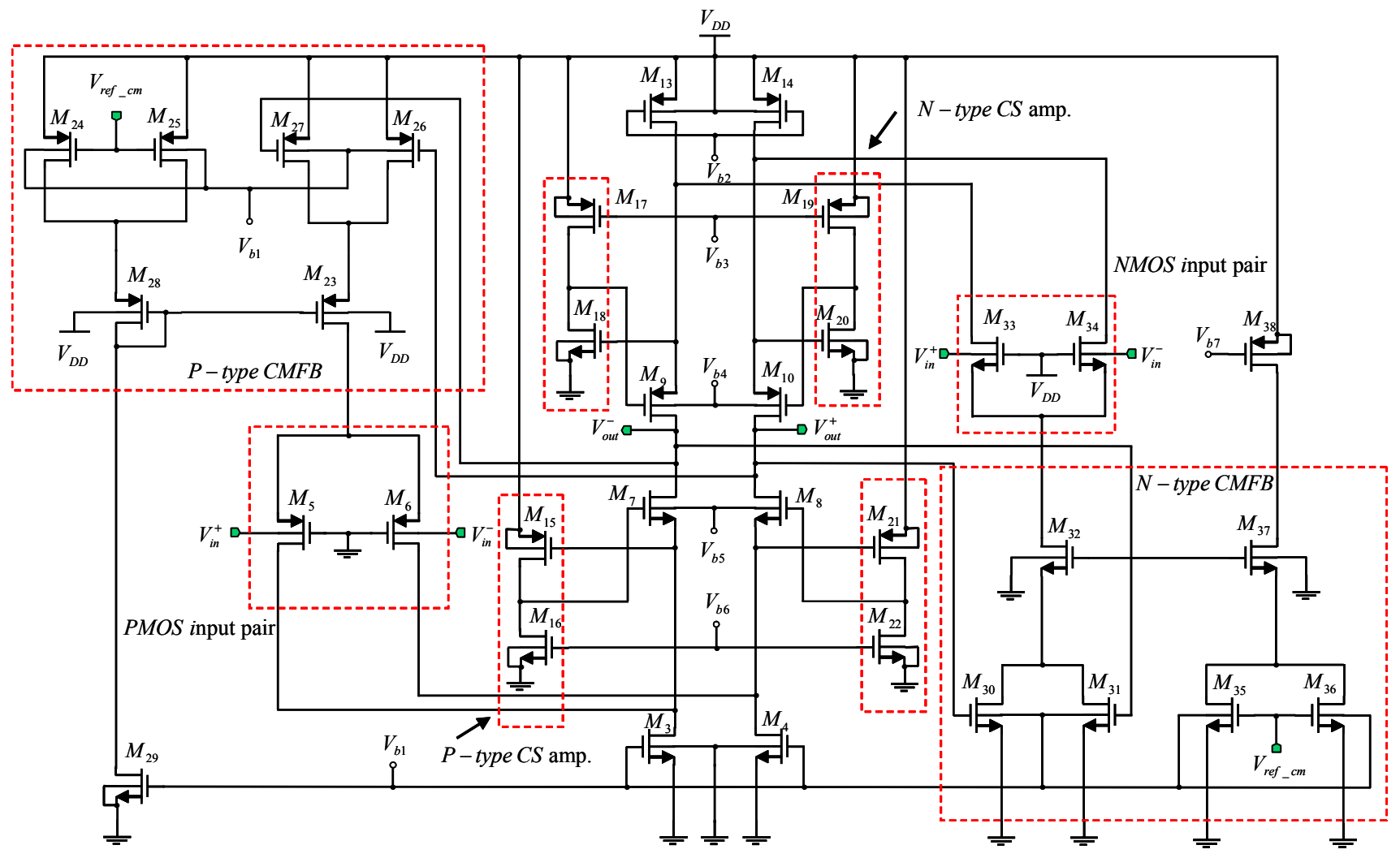

Figure 1. The amplifier core of an OTA

strategy supports rail-to-rail ( 0 volt to 0.8 volt) operation of the amplifier, thus the input common mode range (ICMR) is extended to the largest possible range. This increased range is achieved since when the input common mode voltage is low, the P-type pair is on and the N-type pair is off (when the input common mode is high, the P-type pair is off and the N-type pair is on). In the middle range, however, both pairs are on, providing a higher overall gain.

\subsection{The Output Branch}

The output branch of the OTA consists of two symmetric common gate $(\mathrm{CG})$ amplifiers $\left(\mathrm{M}_{7}\right.$ and $\left.\mathrm{M}_{8}\right)$. Both amplifiers have cascode current loads $\left(\mathrm{M}_{9}\right.$ and $\mathrm{M}_{13}$ and $\mathrm{M}_{10}$ and $\left.\mathrm{M}_{14}\right)$ to increase the gain. The bias current is provided to $M_{7}$ and $M_{8}$ by the current sources $\mathrm{M}_{3}$ and $\mathrm{M}_{4}$, respectively, which also operate as current loads for the P-type input pair $\left(\mathrm{M}_{5}\right.$ and $\left.\mathrm{M}_{6}\right)$. Note that a complementary structure is also implemented for the N-type input pair. Transistors $\mathrm{M}_{13}$ and $\mathrm{M}_{14}$ act as current sources for the N-type input pair.

\subsection{Auxiliary CS Amplifiers}

Auxiliary common source (CS) amplifiers $\left(\mathrm{M}_{15}, \mathrm{M}_{16}, \mathrm{M}_{21}\right.$, and $\mathrm{M}_{22}$, and $\mathrm{M}_{17}, \mathrm{M}_{18}, \mathrm{M}_{19}$, and $\mathrm{M}_{20}$ shown in Figure 1) provide a target open loop gain of at least $60 \mathrm{~dB}$. In this way, stacking multiple transistors in the output branch is avoided, providing more overdrive voltage to maintain the transistors in the saturation region, while simultaneously increasing the voltage gain. The output of the CS amplifier is connected to the gate of the CG amplifier so as to maintain an almost constant source voltage. This source node is fed back as the input voltage to the CS amplifier. In this way, the local feedback action reduces the variations in the bias current when the source voltage of the CG amplifier changes, thereby increasing the output resistance.

\subsection{Common Mode Feedback (CMFB)}

The CMFB circuit $\left(\mathrm{M}_{24}, \mathrm{M}_{25}, \mathrm{M}_{26}\right.$, and $\mathrm{M}_{27}$ and $\mathrm{M}_{30}, \mathrm{M}_{31}, \mathrm{M}_{35}$, and $\mathrm{M}_{36}$ shown in Figure 1) is used to suppress the variations in the output common mode, particularly in applications with feedback. These variations occur due to mismatches among the transistors. These mismatches cause a difference between the DC operating voltages in the outputs $\left(\mathrm{V}_{\text {out }}^{+}\right.$and $\left.\mathrm{V}_{\text {out }}^{-}\right)$. Furthermore, by forcing the output common mode to a specific level (normally halfway between $\mathrm{V}_{\mathrm{DD}}$ and ground), the range of the input common mode is increased.

The CMFB circuit was first proposed in [5]. In this configuration, transistors $\mathrm{M}_{24}, \mathrm{M}_{25}, \mathrm{M}_{26}$, and $\mathrm{M}_{27}$ operate in the linear region, acting as voltage controlled resistors. When the DC operating point at the output differs from the target common mode voltage, a change in the tail current of the input pair occurs, resulting in an increment or decrement in the bias currents. This 
effect restores the DC operating point to the desired voltage level.

\section{BIAS CIRCUIT AND REFERENCE CURRENT GENERATOR}

In order to ensure that the transistors operate in the saturation region (or in the linear region for some of the transistors in the CMFB circuit), fixed bias voltages are applied either to the gate or body of the transistors. The bias voltage generator circuit is shown in Figure 2.

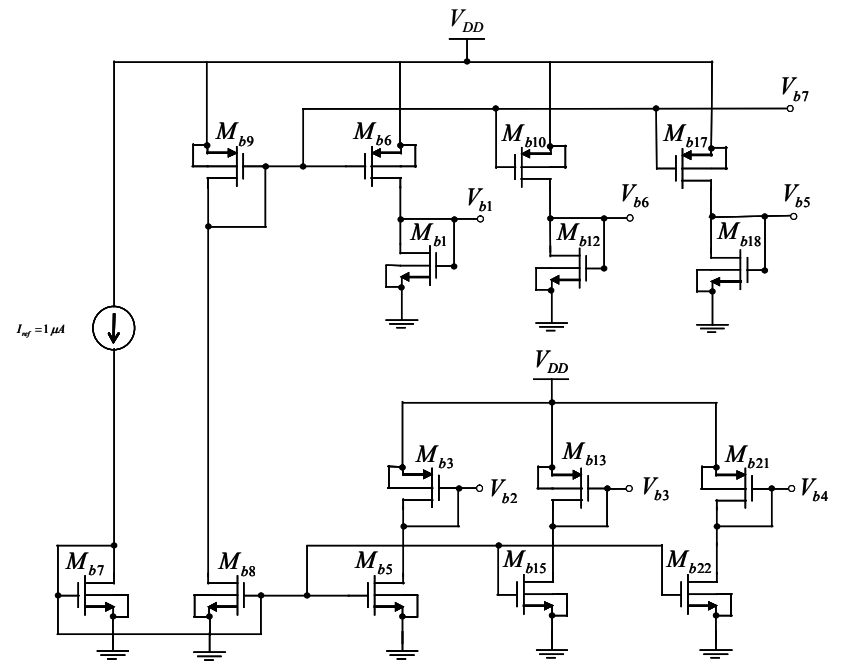

Figure 2. Bias voltage generator circuit

Due to limited voltage headroom, simple voltage dividers are used to generate the bias voltages $\left(\mathrm{V}_{\mathrm{b} 1}-\mathrm{V}_{\mathrm{b} 7}\right.$ in Figure 1). Transistors $\mathrm{M}_{\mathrm{b} 6}, \mathrm{M}_{\mathrm{b} 10}$, and $\mathrm{M}_{\mathrm{b} 17}$ act as current mirrors for the transistor $\mathrm{M}_{\mathrm{b} 9}$, providing the appropriate currents to generate voltages $\mathrm{V}_{\mathrm{b} 1}$, $\mathrm{V}_{\mathrm{b} 5}$, and $\mathrm{V}_{\mathrm{b} 6}$. A complementary structure is also applied to generate voltages $\mathrm{V}_{\mathrm{b} 2}, \mathrm{~V}_{\mathrm{b} 3}$, and $\mathrm{V}_{\mathrm{b} 4}$. Transistor $\mathrm{M}_{\mathrm{b} 8}$ is the current mirror of $\mathrm{M}_{\mathrm{b} 7}$, which is biased with a constant current source $I_{r e f}$ $(1 \mu \mathrm{A})$.

A low-sensitivity reference current generator circuit is illustrated in Figure 3. Because the gate and source of $M_{c 4}$ and $M_{c 2}$ are common for both transistors, and the aspect ratios are equal, $I_{D c 4}$ $=I_{D c 2}$ (neglecting channel length modulation). Furthermore, note that $V_{G S c 3}=V_{G S c 1}+I_{D c l} R_{S c l}$. Thus,

$$
\sqrt{\frac{2 \cdot I_{D c 2}}{\mu_{n} \cdot C_{o x} \cdot(W / L)_{M c 3}}}=\sqrt{\frac{2 \cdot I_{D c 2}}{\mu_{n} \cdot C_{o x} \cdot K \cdot(W / L)_{M c 3}}}+I_{D c 2} \cdot R_{S c 1},
$$

where $K$ is the ratio between the aspect ratios of $\mathrm{M}_{\mathrm{c} 1}$ and $\mathrm{M}_{\mathrm{c} 3}$. Rearranging this expression,

$$
I_{D c 2}=\frac{2}{\mu_{n} \cdot C_{o x} \cdot(W / L)_{c 3}} \cdot \frac{1}{R^{2}} \cdot\left(1-\frac{1}{\sqrt{K}}\right)^{2} .
$$

In the target circuit, $K=1.6$ and $R=5 \mathrm{~K} \Omega$, therefore $I_{D c 2}=4 \mu \mathrm{A}$. As expected, the current is independent of the supply voltage (to a first order approximation). Transistor $M_{c 5}$ mirrors this current to generate a stable $1 \mu \mathrm{A}$ reference current, which is used in the bias circuit as shown in Figure 2.

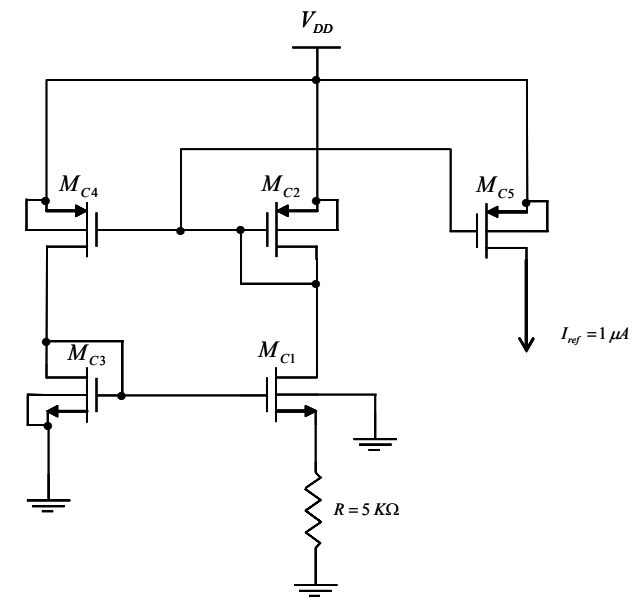

Figure 3. Low sensitivity reference current generator

The aspect ratios of each of the transistors used in the OTA core (Figure 1), the bias circuit (Figure 2) and the reference current generator (Figure 3) are listed in Tables 1, 2, and 3, respectively.

Table 1. Aspect ratios of the transistors used in the amplifier core

\begin{tabular}{|c|c|c|c|}
\hline Transistor & Width & Length & Ratio \\
\hline \hline $\mathrm{M}_{3}, \mathrm{M}_{4}, \mathrm{M}_{29}$ & $5.40 \mu \mathrm{m}$ & $360 \mathrm{~nm}$ & 15.0 \\
\hline $\mathrm{M}_{5}, \mathrm{M}_{6}$ & $16.20 \mu \mathrm{m}$ & $360 \mathrm{~nm}$ & 45.0 \\
\hline $\mathrm{M}_{7}, \mathrm{M}_{8}$ & $2.52 \mu \mathrm{m}$ & $360 \mathrm{~nm}$ & 7.0 \\
\hline $\mathrm{M}_{9}, \mathrm{M}_{10}$ & $10.80 \mu \mathrm{m}$ & $360 \mathrm{~nm}$ & 30.0 \\
\hline $\mathrm{M}_{13}, \mathrm{M}_{14}$ & $21.60 \mu \mathrm{m}$ & $360 \mathrm{~nm}$ & 60.0 \\
\hline $\mathrm{M}_{15}, \mathrm{M}_{17}, \mathrm{M}_{19}, \mathrm{M}_{21}$ & $5.04 \mu \mathrm{m}$ & $360 \mathrm{~nm}$ & 14.0 \\
\hline $\mathrm{M}_{16}, \mathrm{M}_{18}, \mathrm{M}_{20}, \mathrm{M}_{22}$ & $1.80 \mu \mathrm{m}$ & $360 \mathrm{~nm}$ & 5.0 \\
\hline $\mathrm{M}_{24}, \mathrm{M}_{25}, \mathrm{M}_{26}, \mathrm{M}_{27}$ & $20.52 \mu \mathrm{m}$ & $360 \mathrm{~nm}$ & 57.0 \\
\hline $\mathrm{M}_{23}, \mathrm{M}_{28}$ & $11.16 \mu \mathrm{m}$ & $360 \mathrm{~nm}$ & 31.0 \\
\hline $\mathrm{M}_{30}, \mathrm{M}_{3}, \mathrm{M}_{35}, \mathrm{M}_{36}$ & $3.42 \mu \mathrm{m}$ & $360 \mathrm{~nm}$ & 9.5 \\
\hline $\mathrm{M}_{3}, \mathrm{M}_{34}$ & $1.98 \mu \mathrm{m}$ & $360 \mathrm{~nm}$ & 5.5 \\
\hline $\mathrm{M}_{32}, \mathrm{M}_{37}$ & $2.88 \mu \mathrm{m}$ & $360 \mathrm{~nm}$ & 8.0 \\
\hline $\mathrm{M}_{38}$ & $18.36 \mu \mathrm{m}$ & $360 \mathrm{~nm}$ & 51.0 \\
\hline
\end{tabular}

Table 2. Aspect ratios of the transistors used in the bias circuit

\begin{tabular}{|c|c|c|c|}
\hline Transistor & Width & Length & Ratio \\
\hline \hline $\mathrm{M}_{\mathrm{b} 1}, \mathrm{M}_{\mathrm{b} 13}$ & $5.04 \mu \mathrm{m}$ & $360 \mathrm{~nm}$ & 14.0 \\
\hline $\mathrm{M}_{\mathrm{b} 3}$ & $10.08 \mu \mathrm{m}$ & $360 \mathrm{~nm}$ & 28.0 \\
\hline $\mathrm{M}_{\mathrm{b} 5}, \mathrm{M}_{\mathrm{b} 22}$ & $2.88 \mu \mathrm{m}$ & $360 \mathrm{~nm}$ & 8.0 \\
\hline $\mathrm{M}_{\mathrm{b} 6}$ & $18.00 \mu \mathrm{m}$ & $360 \mathrm{~nm}$ & 50.0 \\
\hline $\mathrm{M}_{\mathrm{b} 7}$ & $0.40 \mu \mathrm{m}$ & $360 \mathrm{~nm}$ & 1.1 \\
\hline $\mathrm{M}_{\mathrm{b} 8}$ & $0.47 \mu \mathrm{m}$ & $360 \mathrm{~nm}$ & 1.3 \\
\hline $\mathrm{M}_{\mathrm{b} 9}$ & $1.73 \mu \mathrm{m}$ & $360 \mathrm{~nm}$ & 4.8 \\
\hline $\mathrm{M}_{\mathrm{b} 10}$ & $15.12 \mu \mathrm{m}$ & $360 \mathrm{~nm}$ & 42.0 \\
\hline $\mathrm{M}_{\mathrm{b} 12}$ & $1.80 \mu \mathrm{m}$ & $360 \mathrm{~nm}$ & 5.0 \\
\hline $\mathrm{M}_{\mathrm{b} 15}$ & $5.40 \mu \mathrm{m}$ & $360 \mathrm{~nm}$ & 15.0 \\
\hline $\mathrm{M}_{\mathrm{b} 17}$ & $9.43 \mu \mathrm{m}$ & $360 \mathrm{~nm}$ & 26.2 \\
\hline $\mathrm{M}_{\mathrm{b} 18}$ & $0.27 \mu \mathrm{m}$ & $360 \mathrm{~nm}$ & 0.7 \\
\hline $\mathrm{M}_{\mathrm{b} 21}$ & $7.02 \mu \mathrm{m}$ & $360 \mathrm{~nm}$ & 19.5 \\
\hline
\end{tabular}


Table 3. Aspect ratios of reference current transistors

\begin{tabular}{|c|c|c|c|}
\hline Transistor & Width & Length & Ratio \\
\hline \hline $\mathrm{M}_{\mathrm{c} 1}$ & $5.52 \mu \mathrm{m}$ & $1380 \mathrm{~nm}$ & 4.0 \\
\hline $\mathrm{M}_{\mathrm{c} 3}$ & $3.80 \mu \mathrm{m}$ & $1520 \mathrm{~nm}$ & 2.5 \\
\hline $\mathrm{M}_{\mathrm{c} 2}, \mathrm{M}_{\mathrm{c} 4}$ & $25.20 \mu \mathrm{m}$ & $1400 \mathrm{~nm}$ & 18.0 \\
\hline $\mathrm{M}_{\mathrm{c} 5}$ & $6.16 \mu \mathrm{m}$ & $1370 \mathrm{~nm}$ & 4.5 \\
\hline
\end{tabular}

\section{CIRCUIT LAYOUT}

The layout of the OTA including the bias circuit and current generator is illustrated in Figure 4. A $0.18 \mu \mathrm{m}$ CMOS twin-well TSMC process is used. Because both the PMOS and NMOS transistors are body biased, a twin-well technology is required in the bulk-driven technique. The double-well only marginally complication the manufacturing process. The use of a twin-well technology, however, is not a significant limitation for the bulkdriven method, since many advanced CMOS technologies use a two well process [6]. As shown in Figure 4, interdigitization and common-centroid methods have been applied in the design of the OTA core so as to decrease mismatches among the transistors [7].

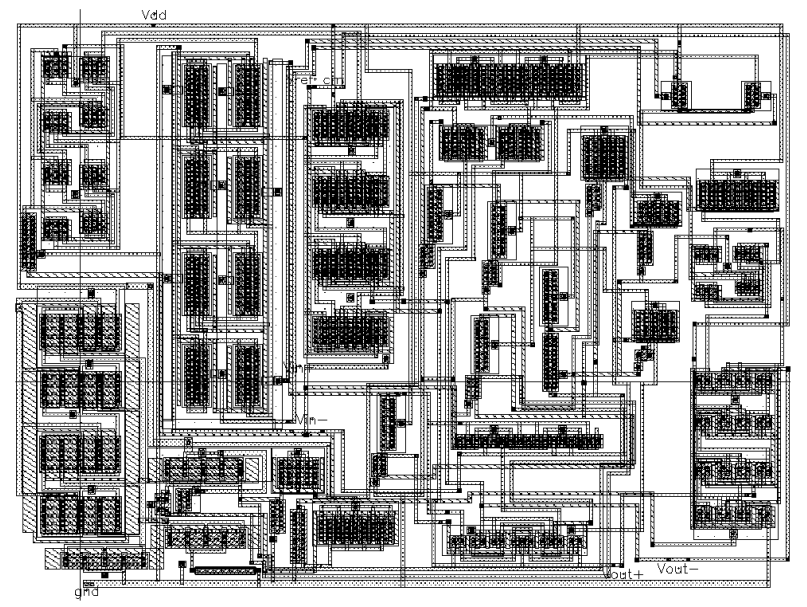

Figure 4. Physical layout of the OTA

\section{OTA PERFORMANCE}

The gain and phase responses of the OTA, which are obtained from post-layout simulations, are shown in Figure 5. The OTA has an open-loop DC gain of $68 \mathrm{~dB}$, a phase margin of $80^{\circ}$, and a unity-gain bandwidth of $93 \mathrm{MHz}$, under a no load condition. For a capacitive load of $1 \mathrm{pF}$, the phase margin increases to $89^{\circ}$ while the unity-gain frequency reduces to $8.12 \mathrm{MHz}$. The OTA operates from a 0.8 volt single power supply and consumes $94 \mu \mathrm{W}$. The simulated ICMR and output swing are $800 \mathrm{mV}$ and $700 \mathrm{mV}$, respectively.

\section{CONCLUSIONS}

The design of an ultra-low voltage, high performance foldedcascode OTA circuit in a standard digital CMOS process is reported in this paper. To accommodate a low power supply voltage $(0.8$ volt $)$, the bulk-driven MOSFET approach is used. The low gain disadvantage of the bulk-driven technique is circum- vented by employing gain boosting amplifiers, permitting the achievement of a DC gain of $68 \mathrm{~dB}$. Due to a lower body transconductance, bulk-driven amplifiers inherently exhibit relatively poor gain. The low gain is the primary reason why previously reported amplifiers [3], [4] have only exhibited a DC gain as high as $45 \mathrm{~dB}$. The primary conclusion of this paper is that bulk-driven amplifiers can be modified to operate with low power supply voltages while still exhibiting performance levels that satisfy the demands of state-of-the-art mixed-signal circuits.

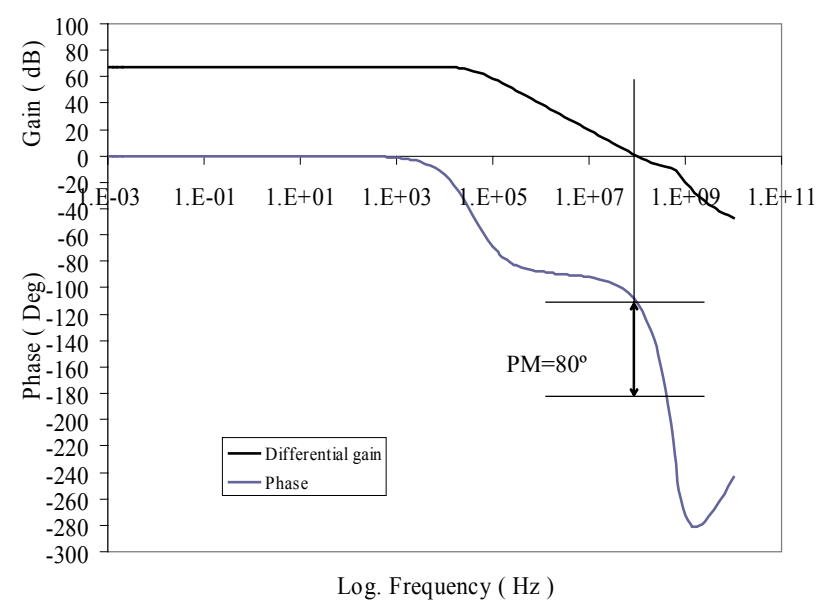

Figure 5. Simulated open loop differential gain and phase vs. log frequency

\section{REFERENCES}

[1] A. Guzinski, M. Bialko, and J. C. Matheau, "Body-Driven Differential Amplifier for Application in Countinous-Time Active-C Filter," Proceedings of the European Conference on Circuit Theory and Design, pp. 315-319, June 1987.

[2] F. Dielacher, J. Houptmann, and J. Resinger, "A Software Programmable CMOS Telephone Circuit," IEEE Journal of Solid-State Circuits, Vol. 26, No. 7, pp. 1015-1026, July 1991.

[3] B. J. Blalock, P. E. Allen, and G. A. Rincon-Mora, "Design 1-V Op Amps Using Standard Digital CMOS Technology," IEEE Transactions on Circuits and Systems II: Analog and Digital Signal Processing, Vol. 45, No. 7, pp. 769-780, July 1998.

[4] F. Bahmani and S. M. Fakhraie, "A Rail-to-Rail, Constant$\mathrm{G}_{\mathrm{m}}$, 1-Volt CMOS Opamp," Proceedings of the IEEE International Symposium on Circuits and Systems, Vol. 2, pp. 669-672, May 2000.

[5] B. Razavi, Design of Analog CMOS Integrated Circuits, New York: McGraw-Hill, 2001.

[6] S. Yan and E. Sanchez-Sinencio, "Low Voltage Analog Circuit Design Techniques: A Tutorial," Institute of Electronics, Information and Communication Engineers Transaction on Analog Integrated Circuits and Systems, Vol. E00-A, pp. 117, February 2000.

[7] R. J. Baker, H. W. Li, and D. E. Boyce, CMOS Circuit Design, Layout, and Simulation, New York: IEEE Press, 1998. 